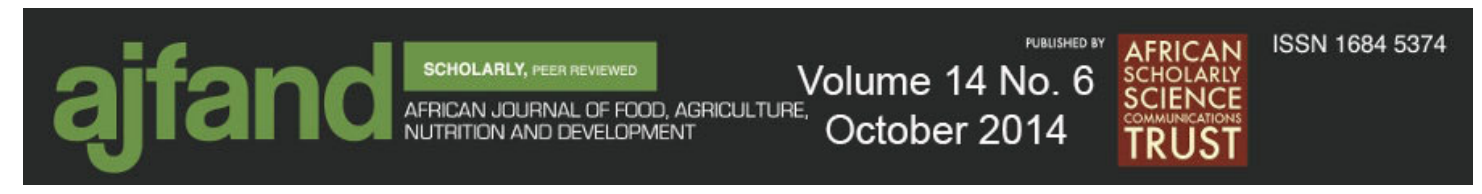

\title{
EFFECT OF DEEP-FAT FRYING ON CHEMICAL PROPERTIES OF EDIBLE VEGETABLE OILS USED BY SENEGALESE HOUSEHOLDS
}

$$
\text { Diop } A^{1 *} \text {, Sarr } S O{ }^{1,2}, \text { Ndao } S^{1} \text {, Cissé } M^{3} \text {, Baldé } M^{1} \text {, Ndiaye } B^{1} \text {, and YM Diop }{ }^{1,2}
$$

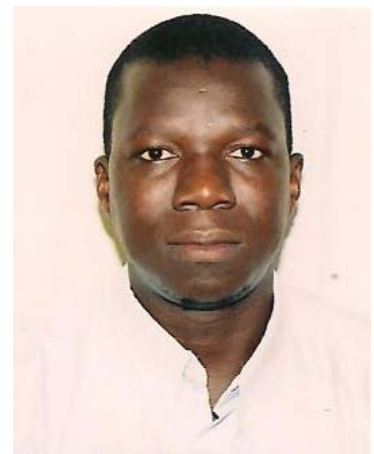

Amadou Diop

*Corresponding author e-mail: diopamadr@yahoo.fr

${ }^{1}$ Laboratoire de Chimie Analytique et Bromatologie, Faculté de Médecine, de Pharmacie et d’Odontologie, Cheikh Anta Diop University, BP 5005, Dakar, Senegal

${ }^{2}$ Laboratoire National de Contrôle des Médicaments, BP 6303 Dakar-Étoile, Dakar, Senegal

${ }^{3}$ Laboratoire d'Analyses et d’Essais, Ecole Supérieure Polytechnique, Cheikh Anta Diop University, Dakar, Senegal. 


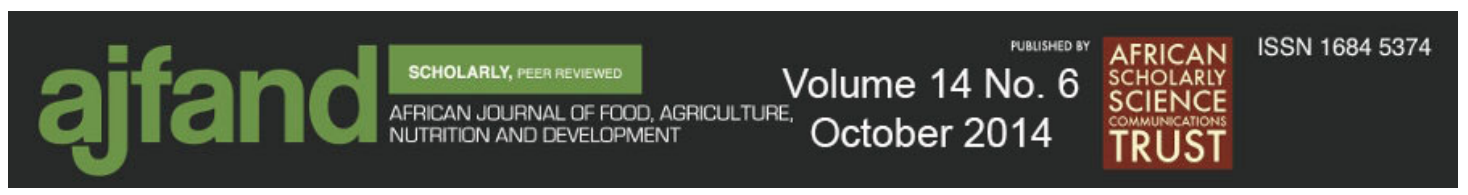

\begin{abstract}
Deep-fat frying performed at high temperatures under atmospheric pressure is a common method of preparing dishes in Senegalese culinary practices. This operation can lead to deterioration of physical, chemical, nutritional and sensory properties of oil, which affects its frying performance. It also results in the production of volatile products such as aldehydes and non volatile fraction which remains in the frying medium. Some of these remaining products have been implicated in producing adverse health effects. Highly oxidized oils may also produce polyaromatic hydrocarbons, which have carcinogenic effect. This work was intended to evaluate the effect of frying on chemical properties of edible vegetable oils. Frying process was applied to meat, fish and potatoes in Senegalese culinary conditions. Ten (10) oil samples, each of three different brands, were purchased from wholesalers and retailers in different neighborhoods of Dakar. The samples were subjected to frying at $220^{\circ} \mathrm{C}$ for $40 \mathrm{~min}$ and then oils were withdrawn in amber bottles samples of which were taken for analysis. Acid value, peroxide value and total polar components were used to evaluate the quality of these oils after initial determination of the iodine value and the moisture and volatile matter content. Acid value increased after $40 \mathrm{~min}$ of frying and values ranged from 0.62 to $1.08 \mathrm{mg} / \mathrm{kg}$ after frying fish, while those for meat and potatoes ranged from 0.39 to 0.73 and 0.37 to $0.51 \mathrm{mg} / \mathrm{kg}$, respectively. Peroxide value increased slightly for peanut oil (A) and sharply for peanut oil (B) and sunflower oil (C). Frying fish led to high values of total polar components whereas those obtained after frying meat and potatoes during 40 min did not exceed $15.27 \%$ except for peanut oil (A). Therefore ${ }_{2}$ frying affects chemical parameter values of edible vegetable oils, which increase at a level depending on the product to be fried. A sharp Total Polar components increase was obtained after frying fish using the three types of oil with values exceeding, sometimes, the maximum level set by the Codex Alimentarius Commission. This latter chemical parameter is considered a good indicator of overall quality of frying oil. Thus in Senegalese culinary practices where frying oil is often reused in families with low-income, such a situation may lead to significant sanitary risks. In view of these results, investigations need to be extended to other types of oil marketed in Senegal.
\end{abstract}

Key words: edible-oils, quality, frying, fish, meat 


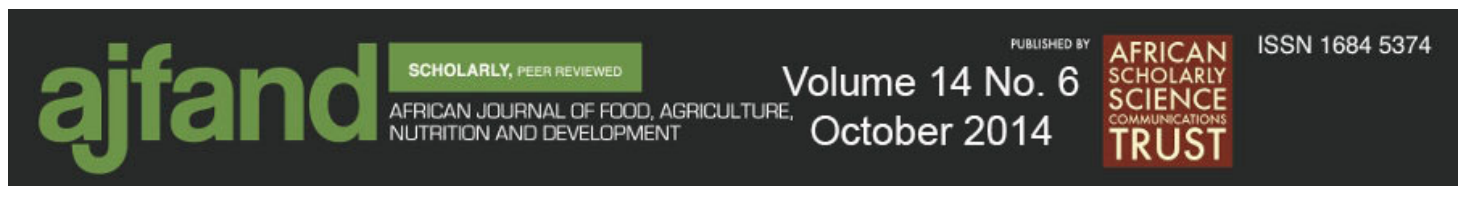

\section{INTRODUCTION}

In Senegalese culinary practices, use of edible oils is very important. Thus, in the Senegalese market, at least, thirty brands of edible vegetable oils locally made or imported can be listed [1]. Beside peanut oils locally made, other types of vegetablebased oils such as palm, sunflower and soy, can be found in the market. Deep-fat frying is one of the oldest and most popular food preparation methods worldwide. As reported by Garayo and Moreira [2], the economy of commercial deep-fat frying has been estimated to be $\$ 6$ billion year ${ }^{-1}$ in the USA and at least twice that amount for the rest of the world. Fried foods have a desirable flavor, color and crispy texture, which make deep-fat fried foods very popular with consumers [3]. During the frying process, oil undergoes changes in physical, chemical, nutritional and sensory properties, which affects its frying performance [4]. The repeated use of oil could affect the shelflife and nutritional quality of fried foods due to the development of rancidity in the frying oil taken up by the products $[5,6]$. High frying temperature, associated with the presence of air and moisture, lead to production of breakdown products that include volatile and non-volatile compounds. These products result from oxidation of unsaturated fatty acids, lipid hydrolysis, and transformation of linear fatty acids in cyclical compounds and fatty acid or lipid polymerization [7]. The intensity of these reactions depends on duration, method of heat treatment, frying medium and type of product $[8,9]$.

The volatile products such as aldehydes are lost during the frying process; the non volatile fraction remains in the frying medium and is absorbed by the fried food. Some of these remaining products have been implicated in producing adverse health effects as they destroy vitamins, inhibit enzymes and could cause mutations or gastrointestinal irritations [10]. Highly oxidized oils may also produce polyaromatic hydrocarbons, which have carcinogenic effects [11].

Therefore, in order to protect the health of the public, it is essential not only to monitor the quality of oils used, but also to determine their stability under normal conditions of use in cooking.

The purpose of this study was to evaluate the effect of frying on chemical properties (acid value, peroxide value and total polar components) of three brands of oils in Senegalese culinary conditions in order to assess whether these oils could be re-used or not. The frying operations were applied on meat, fish and potatoes which are common products prepared by this way in Senegal.

\section{MATERIALS AND METHODS}

\section{Materials and reagents}

Materials used for preparation and analysis consisted of conventional laboratory glassware, cooking utensils for reproduction of cooking techniques, an AC-digital electronic thermometer (Estar Electronic \& Instrument Co., Zhejiang, China) for cooking temperature monitoring, a Sartorius analytical balance (precision $10^{-4} \mathrm{~g}$ ) (Rainbow Ciotechnology Co., Taipei, Taiwan), glass columns of about 45 x $2.1 \mathrm{~cm}$ i.d. 
packed with silica gel prepared in slurry form in hexane and an oven. All chemicals used were of analytical grade unless otherwise specified. Double distilled water was used.

\section{Methods}

\section{Sampling method}

This present study focused on three brands of oil commonly consumed in Senegal: Niinal oil (brand A), Niani oil (brand B), Lessieur tournesol oil (brand C). Ten (10) samples of each brand were purchased from wholesalers and retailers in different neighborhoods of Dakar. Samples collected are presented in a single package volume from $250 \mathrm{~mL}$ to $1 \mathrm{~L}$. Thirty (30) samples were obtained and kept in their original packaging under ambient conditions.

\section{Frying methods}

Fresh meat pieces, fish and potatoes were purchased from the local market, thoroughly washed and cleaned manually. The pieces were then mixed with $6 \mathrm{~g}$ of salt, $5 \mathrm{~g}$ of broth and $10 \mathrm{~g}$ of garlic and fried in an aluminum cooking-pot with $250 \mathrm{~mL}$ heated oil maintained at $220^{\circ} \mathrm{C}$ for $6 \mathrm{~min}$. Frying time was $20 \mathrm{~min}$ for meat and $10 \mathrm{~min}$ for fish and potatoes. A total of $500 \mathrm{~g}$ of each was fried in $40 \mathrm{~min}$.

\section{Oils samples}

After 40 min of frying, the oil was cooled to room temperature, then withdrawn in amber glass bottles and stored at $-20^{\circ} \mathrm{C}$ until analysis.

\section{Analytical methods}

\section{Determination of acid value (AV)}

Acid value was determined according to ISO 660: 2009 as follows [12]: a known weight $(2 \mathrm{~g})$ of the oil was dissolved in a neutral ethyl alcohol $(30 \mathrm{~mL})$; the mixture was boiled in a water bath for 2 min and then titrated with a potassium hydroxide solution $(0.1 \mathrm{~N})$ in the presence of phenolphthalein as an indicator. Each sample was analyzed in triplicate and acid value is expressed as $\mathrm{mg} \mathrm{KOH}$ required to neutralize the acidity in one gram of oil.

\section{Determination of iodine value (IV)}

The iodine value was determined according to ISO 3961: 2009 [13]. A known weight of oil $(0.2 \mathrm{~g})$ was dissolved in chloroform $(20 \mathrm{ml})$ and, then Hanus iodine ( $\mathrm{I}_{2}+\mathrm{Br} /$ ACOH) solution $(25 \mathrm{~mL})$ was added and left in the dark for $30 \mathrm{~min}$. A potassium iodide solution $(10 \mathrm{~mL}, 15 \%)$ was added, followed by freshly distilled water $(100 \mathrm{~mL})$ and the excess iodine was titrated with sodium thiosulphate $(0.1 \mathrm{~N})$ until the yellow color of solution had almost disappeared. Titration was continued after adding a few drops of starch as an indicator until the blue color had entirely disappeared. A blank was conducted where the total halogen content of the Hanus solution (25 mL) was determined by a sodium thiosulphate solution without the addition of oil. Each sample 


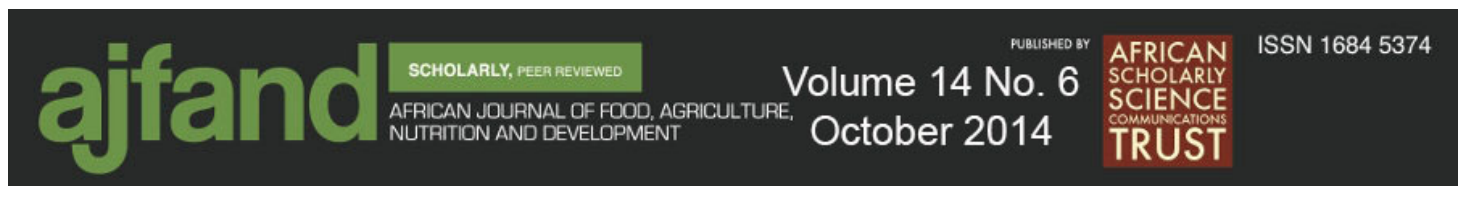

was analyzed in triplicate and iodine value is expressed as grams of $\mathrm{I}_{2}$ absorbed by 100g oil.

\section{Determination of peroxide value (PV)}

The peroxide values were determined according to ISO 3960: 2007 [14]. A known weight of the oil sample (2.5 g) was dissolved in a mixture consisting of glacial acetic acid: chloroform (30 mL, 3:2, v/v), then freshly prepared saturated potassium iodide solution $(1 \mathrm{~mL})$ was added. Distilled water $(30 \mathrm{ml})$ was added then titrated slowly with a sodium thiosulphate solution $(0.1 \mathrm{~N})$ in the presence of a starch solution $(1 \%)$ as an indicator. Each sample was analyzed in triplicate and peroxide value is expressed as milliequivalents of $\mathrm{O}_{2} \mathrm{~kg}^{-1}$ oil.

\section{Determination of moisture and volatile matter content (WC)}

The moisture and volatile matter content was determined according to ISO: 662: 1998 as follows [15]. $5 \mathrm{~g}$ of fat was placed in a previously dried and weighed crystallizer. Then, the whole was placed in an oven at $105^{\circ} \mathrm{C}$ for 30 minutes and weighed after cooling in a desiccator. This step was repeated again. Loss on drying is ended when decrease of sample weight did not exceed $0.05 \%$ per half hour.

\section{Determination of total polar components (TP)}

Semi-solid and solid samples were heated at temperature just above their melting point and filtered to remove visible impurities. Then $2.5 \mathrm{~g}$ sample precisely weighed was placed in a $50 \mathrm{~mL}$ flask and dissolved with $20 \mathrm{~mL}$ of a solvent mixture composed of 87\% petroleum ether and 13\% diethyl ether with slight heating. After cooling at room temperature and adjusting to volume with the same solvent mixture, polar and nonpolar components were separated by chromatography by pouring the sample at the top of the column. Elution was done with $150 \mathrm{~mL}$ of the previous solvent mixture. The eluate was collected in a round bottom flask then concentrated by distilling the solvent on a rotary evaporator at about $40^{\circ} \mathrm{C}$ to about $5 \mathrm{ml}$. The remaining solvent was then evaporated to dryness under stream of analytical grade nitrogen (99.999\%). Each sample was analyzed in triplicate.

\section{Quality control parameters}

Acid value, peroxide value and total polar components were determined before and after frying. Iodine value was not used as quality control parameter but only to provide information about the degree of unsaturation of oils studied. Methods described above were used to determine these various parameters.

\section{RESULTS}

\section{Labeling}

Labeling of some oil types was not done according to the requirements of the Codex Alimentarius. For instance, the list of ingredients, amount of certain ingredients or categories of ingredients, name of manufacturer or importer and batch number on peanut oil $\mathrm{A}$ and $\mathrm{B}$ were not mentioned on the packaging. For sunflower oil $\mathrm{C}$, all requirements in terms of labeling were met except the name of the importer. 


\section{Iodine value (IV)}

Brand C oil had an IV of $56.38 \mathrm{gI}_{2} / 100 \mathrm{~g}$, which was lower than that of brands A (89.88 $\left.\mathrm{gI}_{2} / 100 \mathrm{~g}\right)$ and $\mathrm{B}\left(99.47 \mathrm{gI}_{2} / 100 \mathrm{~g}\right)$. Thus, oils collected correspond to nondrying ones characterized by an iodine value less than 100. Such a result is consistent with the nature of oils indicated by manufacturers on packaging. Brands A and B samples correspond to peanut oil (IV= 86-107) while brand C corresponds to sunflower oil (IV= 78-90).

\section{Moisture and volatile matter content (WC)}

Results obtained were $0.20,0.19$ and $0.12 \%$ for oils A, B and C, respectively.

\section{Acid value (AV)}

Results of acid value are presented in the Tables 1, 2, 3 and show the same trend for all the three brands. For Brand A an average acid value of $0.33 \mathrm{mg}$ of $\mathrm{KOH} / \mathrm{g}$ was obtained before frying, which increases to reach a value of $1.08,0.73$ and $0.51 \mathrm{mg}$ of $\mathrm{KOH} / \mathrm{g}$ after frying fish, meat and potatoes, respectively.

For Brand $\mathrm{B}$, an initial average acid value of $0.28 \mathrm{mg}$ of $\mathrm{KOH} / \mathrm{g}$ was obtained which increases as to be equal to $0.41,0.79$ and $0.34 \mathrm{mg}$ of $\mathrm{KOH} / \mathrm{g}$ after frying meat, fish and potatoes, respectively.

The same trend was found for the brand $\mathrm{C}$ which exhibited the lowest initial average acid value $(0.15 \mathrm{mg}$ of $\mathrm{KOH} / \mathrm{g})$. Higher acid values of $0.39,0.62$, and $0.37 \mathrm{mg}$ of $\mathrm{KOH} / \mathrm{g}$ were obtained after frying meat, fish and potatoes, respectively.

\section{Peroxide Value (PV)}

Tables 4, 5 and 6 show results of peroxide value obtained for the three brands of oil. Values obtained with peanut oil A were generally higher after frying than before, except for sample 6, 8 and 10 which exhibited a reverse trend. For these samples, values of PV were 42.90, 14.52 and $14.89 \mathrm{mEqO} / \mathrm{kg}$ before frying, respectively. After frying, values did not exceed 32.24, 16.07 and $18.13 \mathrm{meqO}_{2} / \mathrm{kg}$ for samples 6, 8 and 10, respectively. Higher values of PV were obtained after frying potatoes than meat and fish.

For peanut oil B, values of PV observed for all the 10 samples showed an increased trend. Indeed, an average value of_-5.52 $\mathrm{meqO}_{2} / \mathrm{kg}$ was obtained before frying, and reached 8.83, 12.87 and $7.17 \mathrm{meqO}_{2} / \mathrm{kg}$ after frying meat, fish and potatoes, respectively. Higher values of PV were also obtained after frying fish than meat and potatoes.

Results of PV of sunflower oils samples showed a same trend than that of peanut oils A and $\mathrm{B}$. A mean value of $6.08 \mathrm{mEqO}_{2} / \mathrm{kg}$ were obtained before frying, and increased to $11.79,18.63$ and $9.14 \mathrm{meqO}_{2} / \mathrm{kg}$ after frying meat, fish and potatoes, respectively. Higher values were found for all samples after frying fish than meat and potatoes. 


\section{Total polar components (TP)}

Peanut oil A samples exhibited low values of TP below 5\% in average before frying (Table 7). These values increased sharply and reached mean values of 26.03, 32.85 and $15.27 \%$ after frying meat, fish and potatoes, respectively. After frying, products followed the order fish $>$ meat $>$ potatoes, according the TP value.

Very low values $(<3 \%)$ of TP were found after analysis of fresh peanut oil B (Table 8). Values of TP increased slightly after frying potatoes for all samples $(\leq 6,05 \%)$. Higher values were obtained after frying meat and fish with average values of 13.37 and $20.87 \%$, respectively. Overall, values obtained were below the suggested discarding limit of $25 \%$.

For sunflower oil C, values of TP were below 5\% for all the ten samples (Table 9). As for peanut oil B a slight increase was observed after frying potatoes during $40 \mathrm{~min}$ (TP $\leq 6.70 \%$ ). For fish and meat, a sharp increase was observed even though results were below the limit of 25\%. Indeed, average values of 22.17 and 14.55 were obtained after frying fish and meat, respectively.

\section{DISCUSSION}

In this study, PV, AV and TP parameters were used to monitor deterioration of fried oil while IV was used to authenticate oil samples.

The iodine value represents the degree of unsaturation. The higher the iodine value, the greater is the unsaturation of specific oil or fat [7]. For the three types of oil, results obtained were consistent with the nature of oils indicated by manufacturers on packaging. Brands A and B samples correspond to peanut oil $(I V=86-107)$ while those of brand C correspond to sunflower oil (IV= 78-90).

For all samples analyzed, water content and volatile matter met the codex specification criteria of $0.2 \%(\mathrm{w} / \mathrm{w})$ [16]. Monitoring of water content in vegetable edible oils is fundamental to assess their ability to storage. High water content induces deterioration of oil quality by hydrolysis. The higher the water content, the faster is the oil degradation [17].

During frying, oil or fat is exposed to air, water and heat. Therefore, thermal, oxidative, and hydrolytic decomposition of the oil may occur. Fats and oils are oxidized to form hydroperoxides, the primary oxidation products. These peroxides are extremely unstable and decompose via fission, dehydration, and formation of free radicals to form a variety of chemical products, such as alcohols, aldehydes, ketones, acids, dimers, trimers, polymers, and cyclic compounds $[18,19]$.

\section{Acid value and effect of frying}

During frying, fats and oils are oxidized to form hydroperoxides that can decompose further to yield the secondary oxidation products, such as alcohols, ketones, aldehydes and acids. In deep-fat frying, however, acids are also produced by hydrolysis of fats to form free fatty acids [9]. Free fatty acids (FFA) content is considered to be an indicator 


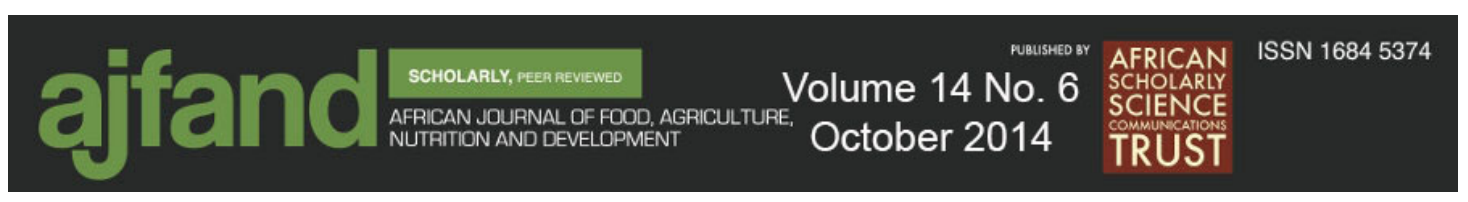

of oil quality in food industry as it leads to the development of off-flavor in oils and fried products.

The initial acid value of fresh oil was found to be equal to $0.33,0.28$ and $0.15 \mathrm{mg}$ of $\mathrm{KOH} / \mathrm{g}$ by average for peanut oils $\mathrm{A}$ and $\mathrm{B}$ and sunflower oil $\mathrm{C}$ respectively. AV was found to increase after 40 min of frying. The increase after frying fish was found to be more important in comparison to frying meat and potatoes. Values obtained ranged from 0.62 to 1.08 after frying fish, while for meat and potatoes they ranged from 0.39 to 0.73 and 0.37 to 0.51 , respectively. For peanut oil A, acid values obtained after frying fish, meat and potatoes were above the Codex standard for refined oils $(0.6 \mathrm{mg}$ of $\mathrm{KOH} / \mathrm{g}$ ) [16]. For peanut oil $\mathrm{B}$ and sunflower oil $\mathrm{C}$, acid value was below Codex specification except after frying fish. Increase in FFA could be attributed to moisture content of the fried product that accelerates the hydrolysis of oil. It is known that water can promote the hydrolysis of triacylglycerols to form a combination of mono and diacylglycerols, glycerol and free fatty acids [20]. Moreover, the FFA content is a dynamic value because at the same time that the acids are being produced, they have sufficient vapor pressure at frying temperatures to evaporate from the surface [21]. However, FFA is not a very reliable parameter for the assessment of the degradation of frying oil, because it is difficult to differentiate FFA formed by oxidation or by hydrolysis [4]. Moreover, low molecular weight FFA may be lost through volatilization during frying [22].

In this study, the AV increase during frying was more important for peanut oil A and B than sunflower oil $C$ (sunflower oil). This may result from the fact that peanut oil has higher hydrolyzed saturated fatty acids that are more resistant to further degradation and remained in the oil during frying. This phenomenon was also reported by Hau et al. [23].

\section{Peroxide value and effects of frying}

Lipid oxidation results in peroxides which are responsible for primary oxidation. Oil, initially forms hydroperoxide compounds, which are a good indicator of lipid oxidation under normal conditions. The initial peroxide value of fresh oil was 12.36, 5.52, 6.08 meqO$/ 2$ for oil A, B, C respectively. Only fresh peanut oil A exceeded the codex maximum level $\left(10 \mathrm{meqO}_{2} / \mathrm{kg}\right)$ [16]. In fact, three samples of it had a PV above the specification limit. This may be due to improper packaging and storage that induce degradation via photo-oxidation. Self-oxidation of unsaturated fats may also appear during storage due to air or oxygen [24]. After meat frying, peroxide value increase slightly for oil A and significantly for oils B and C. Such a phenomenon was observed after frying fish where all PV exceeded the maximum codex level. After frying potatoes, oil A peroxide value was above the specification limit while, oils B and C showed a little increase. Other authors also reported increase in peroxide value of oil upon heating [25, 26]. Moreover, poly-unsaturated oils have reduced stability at elevated temperatures; unsaturated fatty acids easily react with oxygen to form peroxides [27]. Peroxide value is useful as an indicator of oxidation at the initial stages; however, it is not related to the frying duration, but to the formation and breakdown of oxidation products. Peroxides are unstable and decompose at frying temperature. They 
may even increase after the sample is taken from the fryer. Hence, it is generally not a very reliable parameter to determine deterioration of frying oil quality [22, 28].

\section{Total polar components}

Measurement of total polar components (TP) is useful in estimating heat misuse in frying oils. Evaluating TP has been characterized as one of the best indicators of the overall quality of frying oils, providing critical information about the total amount of newly formed compounds having higher polarity than triacylglycerols [29]. TP in fresh frying oil include sterols, tocopherols, mono- and diglycerides, free fatty acids, and other oil-soluble components that are more polar than triglycerides [30]. In this study, the content of TP in fresh oils was less than 5\% for all the three brands. During frying, fats and oils undergo oxidation and/or hydrolysis to produce polar products, such as epoxides, aldehydes, ketones, alcohols, acids, mono- and diglycerides. Such a process leads to an increase of TP. After 40 minutes of frying meat and potatoes, the amount of polar components did not exceed $15.27 \%$ except for oil A where $26.03 \%$ were reached after frying meat. A more important increase was observed after frying fish; TP were 32.85, 20.87 and $22.17 \%$ for oil A, B and C respectively. Other authors [27, 31] also reported an increase in total polar components with heating, results that concur with findings in this study. Formation of total polar components, which indicates oil deterioration is strongly related to primary and secondary oxidation that takes place during frying. When the amount of total polar components reaches $25 \%$ levels, oil is considered to be thermally degraded and should be replaced with fresh oil [26]. Oxidation of oil is caused by aeration during frying that is promoted by bubbling of water provided by food. Thermal decomposition of lipids is generally observed during advanced heating to temperatures above $200{ }^{\circ} \mathrm{C}$ and results in the appearance of cyclic polymers and monomers [32].

\section{CONCLUSION}

Before frying, all the three types of oil used in this study met the Codex specifications in terms of water content, acid value, peroxide value, total polar components. Frying process has affected chemical properties of edible vegetable oils. Acid value, peroxide value and total polar components showed an increase after frying and reached a level depending on the product to be fried. A sharp TP increase was obtained after frying fish for the different types of oil with values exceeding sometimes the codex maximum level. This latter chemical parameter is considered as a good indicator of overall quality of frying oil. Thus, in Senegalese culinary practices where frying oil is often re-used in family with low-income, such a situation may lead to significant sanitary risks. In view of these results, investigations need to be extended to other types of oil marketed in Senegal. Also, studies need to be done to assess which of these oils exhibit better stability during deep-fat frying. 


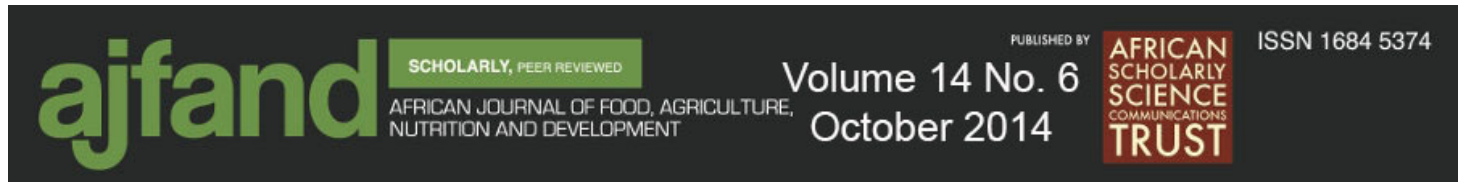

Table 1: Mean acid value (mg of $\mathrm{KOH} / \mathrm{g}$ ) of Niinal oil (brand A) samples before and after frying

\begin{tabular}{|c|c|c|c|c|}
\hline \multirow[t]{2}{*}{ Sample code } & \multirow[t]{2}{*}{ Before frying } & \multicolumn{3}{|c|}{ After frying } \\
\hline & & Meat & Fish & Potatoes \\
\hline 1 & 0.32 & 0.67 & 1.00 & 0.49 \\
\hline 2 & 0.31 & 0.78 & 0.96 & 0.51 \\
\hline 3 & 0.33 & 0.72 & 1.03 & 0.5 \\
\hline 4 & 0.32 & 0.76 & 1.01 & 0.53 \\
\hline 5 & 0.33 & 0.72 & 1.04 & 0.56 \\
\hline 6 & 0.32 & 0.85 & 1.12 & 0.56 \\
\hline 7 & 0.31 & 0.69 & 1.03 & 0.5 \\
\hline 8 & 0.32 & 0.68 & 1.01 & 0.48 \\
\hline 9 & 0.33 & 0.76 & 0.98 & 0.49 \\
\hline 10 & 0.32 & 0.72 & 1.02 & 0.48 \\
\hline Average & 0.33 & 0.73 & 1.08 & 0.51 \\
\hline S.D & 0.03 & 0.05 & 0.23 & 0.03 \\
\hline
\end{tabular}

Key: SD= Standard Deviation; Values for each coded sample are mean of triplicate 


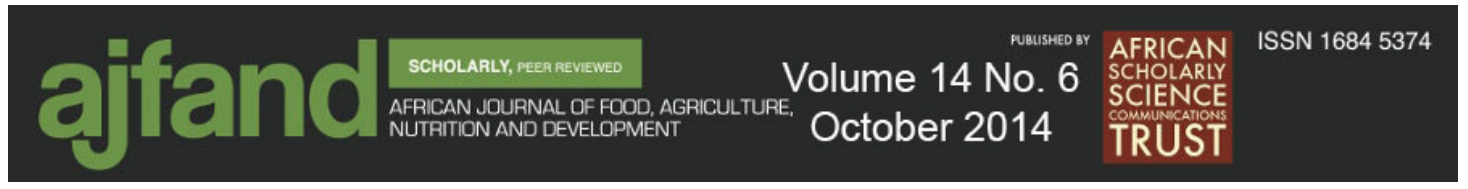

Table 2: Mean acid value (mg of $\mathrm{KOH} / \mathrm{g}$ ) of Niani oil (brand B) samples before and after frying

\begin{tabular}{|c|c|c|c|c|}
\hline \multirow[t]{2}{*}{ Sample code } & \multirow[t]{2}{*}{ Before frying } & \multicolumn{3}{|c|}{ After frying } \\
\hline & & Meat & Fish & Potatoes \\
\hline 1 & 0.28 & 0.4 & 0.78 & 0.34 \\
\hline 2 & 0.27 & 0.38 & 0.81 & 0.35 \\
\hline 3 & 0.29 & 0.36 & 0.79 & 0.32 \\
\hline 4 & 0.28 & 0.45 & 0.78 & 0.34 \\
\hline 5 & 0.27 & 0.40 & 0.83 & 0.34 \\
\hline 6 & 0.28 & 0.43 & 0.78 & 0.36 \\
\hline 7 & 0.29 & 0.36 & 0.78 & 0.35 \\
\hline 8 & 0.3 & 0.43 & 0.81 & 0.36 \\
\hline 9 & 0.27 & 0.45 & 0.78 & 0.34 \\
\hline 10 & 0.28 & 0.44 & 0.81 & 0.32 \\
\hline Average & 0.28 & 0.41 & 0.79 & 0.34 \\
\hline S.D & 0.01 & 0.03 & 0.02 & 0.01 \\
\hline
\end{tabular}

Key: SD= Standard Deviation; Values for each coded sample are mean of triplicate 


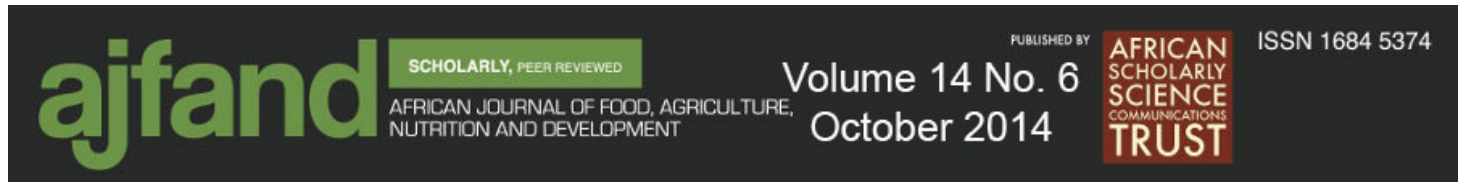

Table 3: Mean acid value (mg of KOH/g) of LESSIEUR TOURNESOL oil (brand C) samples before and after frying

\begin{tabular}{lcccc}
\hline Sample code & Before frying & \multicolumn{3}{c}{ After frying } \\
\cline { 3 - 5 } & & Meat & Fish & Potatoes \\
\hline 1 & 0.11 & 0.38 & 0.60 & 0.36 \\
2 & 0.14 & 0.38 & 0.63 & 0.38 \\
3 & 0.17 & 0.41 & 0.63 & 0.36 \\
4 & 0.12 & 0.40 & 0.60 & 0.36 \\
5 & 0.15 & 0.39 & 0.64 & 0.41 \\
6 & 0.17 & 0.38 & 0.60 & 0.36 \\
7 & 0.14 & 0.40 & 0.63 & 0.39 \\
8 & 0.14 & 0.40 & 0.63 & 0.36 \\
9 & 0.17 & 0.39 & 0.60 & 0.38 \\
S.D & 0.17 & 0.38 & 0.65 & 0.40 \\
\hline Average & 0.15 & 0.39 & 0.62 & 0.37 \\
\hline & 0.01 & 0.02 & 0.02 \\
\hline
\end{tabular}

Key: SD= Standard Deviation; Values for each coded sample are mean of triplicate 


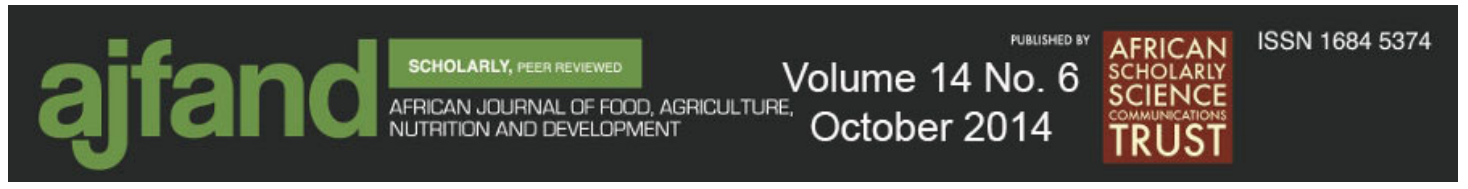

Table 4: Mean peroxide value ( $\mathrm{meqO}_{2} / \mathrm{kg}$ ) of Niinal oil (brand A) samples before and after frying

\begin{tabular}{lcccc}
\hline Sample code & Before frying & \multicolumn{3}{c}{ After frying } \\
\cline { 3 - 5 } & & Meat & Fish & Potatoes \\
\hline 1 & 4.03 & 10.27 & 11.66 & 15.63 \\
2 & 8.25 & 13.02 & 11.17 & 18.45 \\
3 & 7.50 & 11.46 & 10.97 & 17.83 \\
4 & 7.20 & 12.01 & 11.52 & 17.24 \\
5 & 8.41 & 12.49 & 11.50 & 18.01 \\
6 & 42.90 & 25.00 & 15.27 & 32.24 \\
7 & 8.58 & 12.33 & 11.42 & 17.64 \\
8 & 14.52 & 10.42 & 11.88 & 16.07 \\
9 & 7.29 & 11.34 & 10.64 & 16.89 \\
10 & 14.89 & 12.80 & 11.46 & 18.13 \\
Average & 12.36 & 13.11 & 11.75 & 18.81 \\
\hline Key: SD=Stany & & 4.28 & 1.29 & 4.80 \\
\hline
\end{tabular}

Key: SD= Standard Deviation; Values for each coded sample are mean of triplicate 


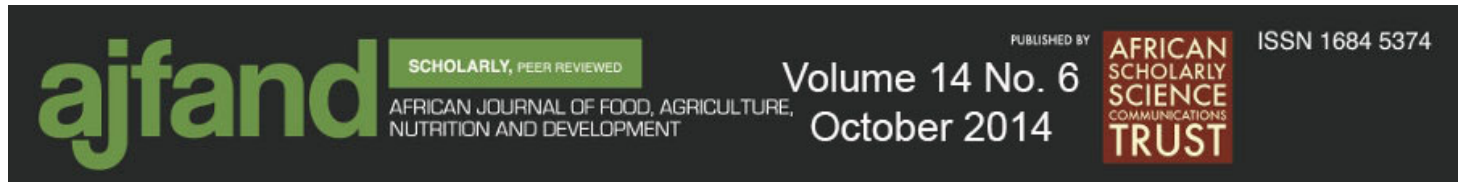

Table 5: Mean peroxide value $\left(\mathrm{meqO}_{2} / \mathrm{kg}\right.$ ) of Niani oil (brand $\left.\mathrm{B}\right)$ samples before and after frying

\begin{tabular}{lcccc}
\hline Sample code & Before frying & \multicolumn{3}{c}{ After frying } \\
\cline { 3 - 5 } & & Meat & Fish & Potatoes \\
\hline 1 & 5.15 & 8.22 & 11.96 & 7.08 \\
2 & 5.95 & 9.41 & 12.84 & 6.34 \\
3 & 6.09 & 8.85 & 12.34 & 8.01 \\
4 & 5.05 & 8.25 & 12.50 & 7.35 \\
5 & 5.25 & 9.40 & 13.94 & 7.85 \\
6 & 6.10 & 8.91 & 13.06 & 6.91 \\
7 & 5.20 & 8.32 & 12.55 & 7.27 \\
8 & 6.01 & 9.22 & 13.53 & 6.56 \\
9 & 5.15 & 8.60 & 12.99 & 7.38 \\
Average & 5.25 & 9.10 & 13.02 & 6.97 \\
\hline 5 & 5.52 & 8.83 & 12.87 & 7.17 \\
\hline & & 0.46 & 0.58 & 0.52 \\
\hline
\end{tabular}

Key: SD= Standard Deviation; Values for each coded sample are mean of triplicate 


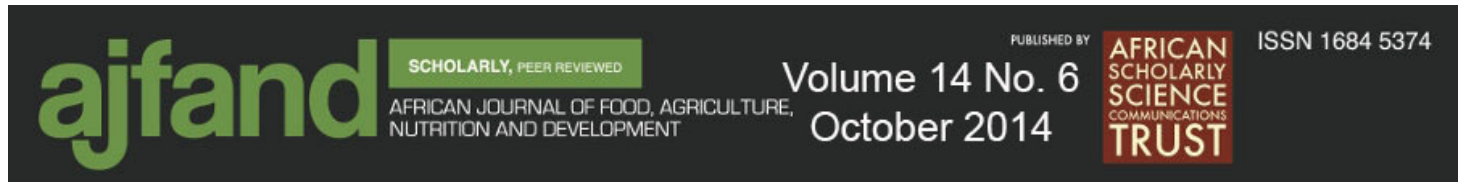

Table 6: Mean peroxide value (meqO $/ \mathrm{kg}_{2}$ of LESSIEUR TOURNESOL oil (brand C) samples before and after frying

\begin{tabular}{lcccc}
\hline Sample code & Before frying & \multicolumn{3}{c}{ After frying } \\
\cline { 3 - 5 } & & Meat & Fish & Potatoes \\
\hline 1 & 5.25 & 11.31 & 18.90 & 8.18 \\
2 & 6.32 & 12.29 & 18.42 & 9.36 \\
3 & 5.85 & 13.02 & 18.24 & 8.03 \\
4 & 6.08 & 11.01 & 18.80 & 9.27 \\
5 & 7.05 & 11.01 & 18.75 & 10.39 \\
6 & 5.92 & 12.47 & 18.22 & 8.94 \\
7 & 5.47 & 11.80 & 19.13 & 8.78 \\
8 & 6.17 & 10.83 & 18.21 & 9.09 \\
9 & 6.88 & 11.96 & 18.73 & 9.47 \\
Average & 5.86 & 12.25 & 18.89 & 9.94 \\
\hline & 6.08 & 11.79 & 18.63 & 9.14 \\
\hline & & 0.73 & 0.33 & 0.73 \\
\hline & & & & \\
\hline
\end{tabular}

Key: SD= Standard Deviation; Values for each coded sample are mean of triplicate 


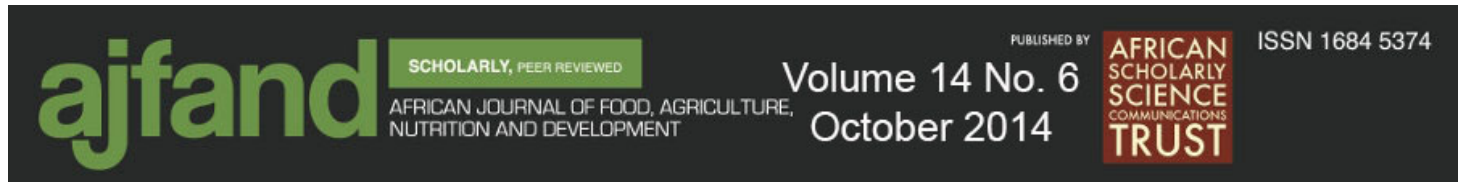

Table 7: Mean total polar components (\%) of Niinal oil (brand A) samples before and after frying

\begin{tabular}{|c|c|c|c|c|}
\hline \multirow[t]{2}{*}{ Sample code } & \multirow[t]{2}{*}{ Before frying } & \multicolumn{3}{|c|}{ After frying } \\
\hline & & Meat & Fish & Potatoes \\
\hline 1 & 4.00 & 25.50 & 32.50 & 15.00 \\
\hline 2 & 4.50 & 26.00 & 33.00 & 14.80 \\
\hline 3 & 3.95 & 24.98 & 32.00 & 14.00 \\
\hline 4 & 4.08 & 25.60 & 33.50 & 15.50 \\
\hline 5 & 4.50 & 26.50 & 32.50 & 14.90 \\
\hline 6 & 5.00 & 27.00 & 34.00 & 17.00 \\
\hline 7 & 4.00 & 25.00 & 32.00 & 15.00 \\
\hline 8 & 4.50 & 26.70 & 33.00 & 16.00 \\
\hline 9 & 4.80 & 27.00 & 33.50 & 15.50 \\
\hline 10 & 4.60 & 26.00 & 32.50 & 15.00 \\
\hline Average & 4.39 & 26.03 & 32.85 & 15.27 \\
\hline S.D & 0.37 & 0.76 & 0.67 & 0.80 \\
\hline
\end{tabular}

Key: SD= Standard Deviation; Values for each coded sample are mean of triplicate 


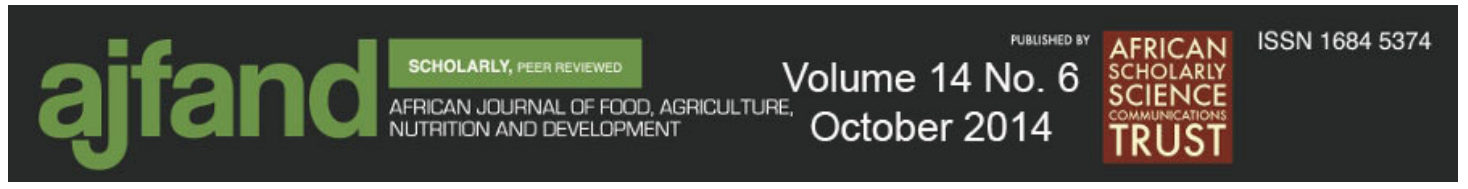

Table 8: Mean total polar components (\%) of Niani oil (brand B) samples before and after frying

\begin{tabular}{|c|c|c|c|c|}
\hline \multirow[t]{2}{*}{ Sample code } & \multirow[t]{2}{*}{ Before frying } & \multicolumn{3}{|c|}{ After frying } \\
\hline & & Meat & Fish & Potatoes \\
\hline 1 & 2.30 & 13.37 & 21.00 & 5.25 \\
\hline 2 & 2.00 & 13.50 & 20.50 & 6.00 \\
\hline 3 & 2.50 & 13.20 & 21.50 & 5.75 \\
\hline 4 & 2.60 & 12.98 & 20.00 & 6.00 \\
\hline 5 & 2.40 & 13.50 & 21.00 & 5.50 \\
\hline 6 & 3.00 & 13.40 & 21.30 & 6.05 \\
\hline 7 & 2.60 & 13.65 & 20.80 & 6.00 \\
\hline 8 & 2.30 & 13.27 & 21.06 & 5.30 \\
\hline 9 & 2.70 & 13.75 & 21.50 & 5.20 \\
\hline 10 & 2.00 & 13.08 & 20.00 & 6.00 \\
\hline Average & 2.44 & 13.37 & 20.87 & 5.70 \\
\hline S.D & 0.31 & 0.24 & 0.55 & 0.35 \\
\hline
\end{tabular}

Key: $\mathrm{SD}=$ Standard Deviation; Values for each coded sample are mean of triplicate 


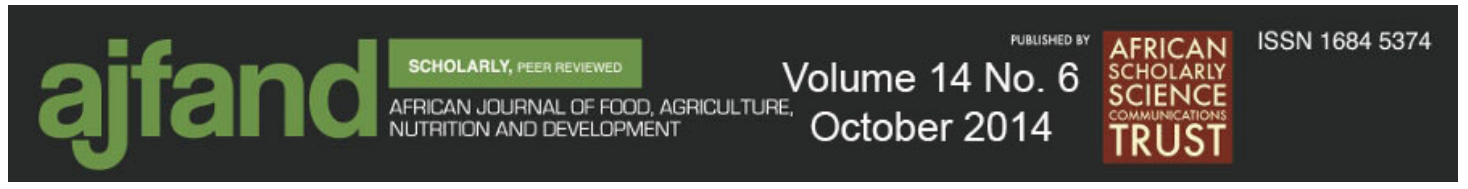

Table 9: Mean total polar components (\%) of LESSIEUR TOURNESOL oil (brand C) samples before and after frying

\begin{tabular}{|c|c|c|c|c|}
\hline \multirow[t]{2}{*}{ Sample code } & \multirow[t]{2}{*}{ Before frying } & \multicolumn{3}{|c|}{ After frying } \\
\hline & & Meat & Fish & Potatoes \\
\hline 1 & 3.00 & 14.00 & 22.00 & 6.40 \\
\hline 2 & 3.20 & 14.50 & 21.95 & 6.20 \\
\hline 3 & 2.80 & 14.08 & 22.50 & 6.00 \\
\hline 4 & 3.50 & 13.95 & 22.00 & 6.50 \\
\hline 5 & 3.00 & 14.30 & 22.04 & 6.30 \\
\hline 6 & 3.50 & 14.00 & 22.03 & 6.00 \\
\hline 7 & 3.00 & 14.00 & 22.00 & 6.40 \\
\hline 8 & 3.00 & 14.05 & 22.70 & 6.50 \\
\hline 9 & 3.05 & 14.60 & 22.50 & 6.70 \\
\hline 10 & 3.00 & 14.00 & 22.00 & 6.40 \\
\hline Average & 3.10 & 14.15 & 22.17 & 6.34 \\
\hline S.D & 0.23 & 0.23 & 0.28 & 0.22 \\
\hline
\end{tabular}

Key: $\mathrm{SD}=$ Standard Deviation; Values for each coded sample are mean of triplicate 


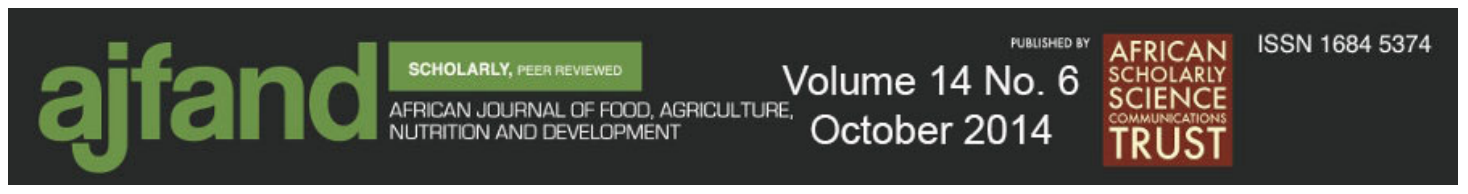

\section{REFERENCES}

1. Kandji NA Etude de la composition chimique et de la qualité d’huiles végétales artisanales consommées au Sénégal. Thèse de pharmacie, 2001; Dakar, №16.

2. Garayo $\mathbf{J}$ and $\mathbf{R}$ Moreira Vacuum frying of potato chips. Journal of Food Engineering, 2002; 55: 181-191.

3. Boskou G, Salta FN, Chiou A, Troullidou E and NK Andrikopoulos Content of trans, trans-2,4-decadienal in deep-fried an pan-fried potatoes. European Journal of Lipid Science and Technology, 2006; 108: 109-115.

4. Ramadan MF, Afify Amer MM and MS Abd El-Rahman Correlation between physicochemical analysis and radical scavenging activity of vegetable oil blends as affected by frying of French fries. European Journal of Lipid Science Technology, 2006; 108: 670-678.

5. Che Man YB and I Jasvir Effect of rosemary and sage extracts on frying performance of refined, bleached and deodorized (RBD) palm olein during deep fat frying. Food Chemistry, 2000; 69: 301-307.

6. Rani M and GS Chauhan Effect of intermittent frying and frying medium on the quality of potato chips. Food Chemistry, 1995; 54: 365-368.

7. Chang SH, Peterson $\mathbf{R}$ and CT Ho Chemical reactions involved in deep fat frying of foods. Journal of American Oil Chemists Society, 1978; 55: 717-728.

8. Blumenthal MM A new look at the chemistry and physics of deep-fat frying. Food Technology, 1991; 45: 68-71.

9. Stevenson SG, Vaisey-Genser $\mathbf{M}$ and NAM Eskin Quality control in the use of deep frying oils. Ibid, 1984; 61: 1102-1108.

10. Clark LW and GW Serbia Safety aspects of frying fats and oils. Food Technology, 1991; 45: 84-94.

11. FAO/WHO. Dietary fats and oils in human nutrition. In: FAO. Food and Nutrition Series, No. 20. Food and Agricultural Organization of the United Nations, Rome, 1988:1-44.

12. ISO. Animal and vegetable fats and oils- Determination of acid value and acidity. ISO 660: 2009, $3^{\text {rd }}$ edn. Switzerland, 2009.

13. ISO. Animal and vegetable fats and oils- Determination of iodine value. ISO 3961: 2009, $4^{\text {th }}$ edn. Switzerland, 2009.

14. ISO. Animal and vegetable fats and oils-Determination of peroxide value. ISO 3960: 2007, $4^{\text {th }}$ edn. Switzerland, 2007. 
15. ISO. Animal and vegetable fats and oils- Determination of moisture and volatile matter content. ISO 662: 1998, $2^{\text {nd }}$ edn. Switzerland, 1998.

16. Codex Alimentarius. Codex standard for named vegetable oils, codex stan 210-1999, amended in 2005 and 2011. Rome, Italy.

17. Harold E, Ronald SK and S Ronald Oils and fats in chemical analysis of food. Edinburgh, London: Churchill, Livingstone, 1981.

18. White PJ Methods for measuring changes in deep-fat frying oils. Food Technology, 1991; 45:75-79.

19. Melton SL, Jafar S, Sykes $\mathbf{D}$ and MK Trigiano Review of stability measurements for frying oils and fried food flavor. Ibid, 1994; 71: 1301-1308.

20. Velasco J, Marmesat S and MC Dobarganes Chemistry of Frying. In: Sahin S, Sumnu G., Taylor and Francis. Deep fat frying of foods. USA, 2008, 33-56.

21. Abd El-Rahman MS, El-Makhzangy A and MF Ramadan Antiradical performance \& physicochemical characteristics of vegetable oils upon frying of French fries: a preliminary comparative study. Journal of Food Lipids, 2006; 13: 259-276.

22. Hau LB, Young PK and LS Hwang Quality assessment of oils during heating and frying. Journal of Chinese Agricultural Chemical Society, 1986; 24: 397405.

23. Nawar WW Lipids in Food chemistry, $3^{\text {rd }}$ Ed. O. R. Fennema (Ed.), Marcel Dekker, New York, 1996: 225-319.

24. Susheelamma NS, Asha MR, Ravi R and AK Vasanth Kumar Comparative studies on physical properties of vegetable oils and their blends after frying. Journal of Food Lipids, 2002; 9: 259-276.

25. Sulthana SN and DP Sen Studies on deep fat frying: changes during heating of oil. Journal of Food Science and Technology, 1979; 16: 208.

26. Serjouie A, Tan CP, Mirhosseini H and Y Bin Che Man Effect of vegetablebased oil blends on physicochemical properties of oils during deep-fat frying. American Journal of Food and Technology, 2010; 5 (5): 310-323.

27. Che-Man YB and WR Wan-Hussin Comparison of the frying performance of refined, bleached and deodorized palm olein and coconut oil. Journal of Food Lipids, 1998; 5: 197-210. 


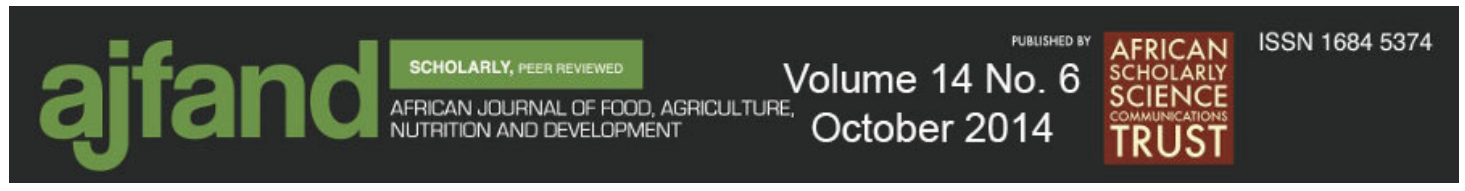

28. Warner $\mathbf{K}$ and $\mathbf{M}$ Gupta Frying quality and stability of low and ultra low linoleic acid soybean oils. Journal of American Oil Chemists Society, 2003; 80: 275-280.

29. Fritsch CW Measurements of Frying Fat Deterioration: A Brief Review. Journal of American Oil Chemists Society, 1981; 58: 272-274.

30. Premavalli KS, Madhura CV and SS Arya Storage and thermal stability of refined cottonseed oil-mustard oil blend. Journal of Food Science and Technology, 1998; 35: 530-532.

31. Abdel-Razek AG, Ragab GH and HS Ali Effect of pre-treatments and frying time on physical and chemical properties of cottonseed oil. Journal of Applied Sciences Research, 2012; 8 (11): 5381-5387.

32. Guillaumin R Evolution des lipides - oxydation enzymatique et auto-oxydation non enzymatique, 1982. In: Multon JL. Conservation et stockage des grains et graines et produits dérivés: céréales, oléagineux, protéagineux, aliments pour animaux. Paris, Lavoisier, 1982: 913-936. 